\title{
The Exploration and Practice of VERICUT Software in the Teaching of "Numerical Control Technology"
}

\author{
Jin Kui ${ }^{\mathrm{a}}$, Zhang Peng \\ Dalian Vocational \& Technical College, China \\ ajk_810912@163.com, bzp1231@163.com
}

Keywords: VERICUT, NC technology, Teaching, Exploration and practice

\begin{abstract}
The course of "numerical control Technology" has many complicated knowledge points and a close integration with the profession. According to this characteristic, combined with the teaching reform of integration of theoretical practice, this paper expounds the features and main functions of VERICUT software and illustrates the feasibility and necessity of software application in the teaching of NC technology in the form of examples and put forward the problems needing attention according to the actual situation.
\end{abstract}

\section{Introduction}

VERICUT, developed by CGTECH company in USA, is a simulation System of NC Machining. It can simulate the NC machining process of CNC lathe, milling machine, machining center, wire cutting machine and multi-axis machine tool and other processing equipment. ${ }^{[1]}$ It can make some of the process, which can not be achieved or observed in ordinary conditions, vividly displayed and thereby enhancing students ' understanding of abstract things, processes and feelings. ${ }^{[3]}$

\section{The Necessity and Feasibility of VERICUT Application in the Teaching of "Numerical Control Technology"}

"Numerical control technology" mainly teaches the NC lathe, the processing center programming, the technology, and the machine tool operation, etc. It is a specialized course in the engineering colleges, which students majored in numerical control must master. It also has a strong theoretical and practical nature. However, in traditional NC teaching, the teacher's theory teaching can only be carried out in the classroom and when involving the specific operation of the machine, students can only rely on the imagination, so it is difficult for students to master the relevant numerical control knowledge. ${ }^{[2]}$ VERICUT solves the above problem by using the computer simulation technology, which has moved the numerical Control machine tool into the computer and uses the projector to display the machine tool and the machine tool operation panel. Teachers use VERICUT to teach theoretical knowledge and practice and implement the theory knowledge in machine tool operation. In this way, teachers can explain knowledge point first, then operate the machine tool, which makes knowledge and practice combine together. Meanwhile, simulation software can move the practical training workshop into classroom. Therefore after the classroom instruction of knowledge point, teacher can layout the actual operation assignments to ask students to process the workpiece in the computer simulation processing program and the workpiece can be measured by the simulation measurement function to test the accuracy of the processing parts. This enables the classroom and the practical training workshop combine closely. Based on this platform, we can do more things. For example: Teachers do not have to repeat the same instructional content each class by using recording function of VERICUT to record a video of the repeated instructional content which teachers need to repeat in each class. They only need to play the recorded video in class. By using its question-making function, processing or operating assignments will be given to students and let them process in the simulation software. In the end of processing, the system can automatically judge right and wrong, and give results. In this way, the efficiency of teaching can be greatly 
improved. The following examples illustrate the application of simulation software in the teaching of the important chapters of NC lathe programming and processing respectively.

\section{Application of VERICUT Software in NC Programming Processing}

NC programming refers to the whole process of complying technical requirements and process requirements of the machined parts, the process sequence of part processing, the working step arrangement in the process, the trajectory and direction of the tool relative to the workpiece movement, the process parameters and the auxiliary action etc according to the drawings, technical requirements and process requirements of the machined parts by the rules, codes and formats stipulated by the numerical control system into files and the information of the program form is made into the controlling media. In traditional classroom teaching, it is already very difficult for students to understand only by imagination of the meaning of the processing code and the application of code format. It is even more difficult for students to figure out how to use the appropriate NC code to express the structural characteristics of workpiece. For example, in Diagram 1, we need to use G73 Imitation Loop code and introduce its code features in programming, it is difficult for students to understand and master the knowledge through the blackboard teaching mode alone. Therefore, numerical control simulation software is used to describe the application of G73 imitating loop code in teaching, it completely simulates the operation panel and screen display of the real NC machine tool, it can verify the correctness of the cutting process of the programmed tool, and is safe and convenient to operate. Students can see the real two-dimensional or three-dimensional simulation processing process (as shown in Figure 2) and students can also visually observe the various situations in the processing the workpiece. This software can help students to master the operation of CNC machine more quickly. It can enable students to form a sense of reality in the simulation of the operation process. Therefore students can be familiar with the CNC machining process, master all kinds of CNC machine tools basic operation and CNC system programming instructions.

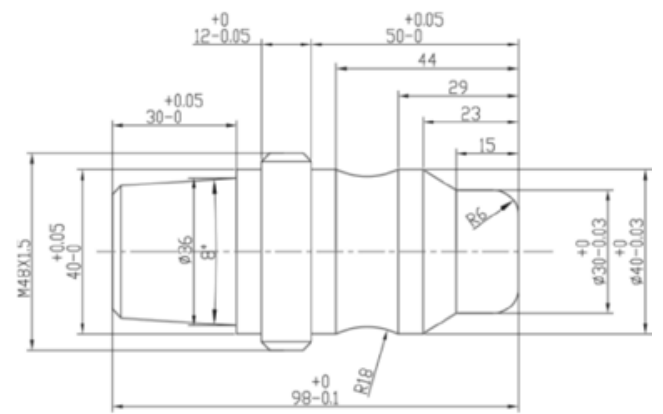

Figure 1 part drawing

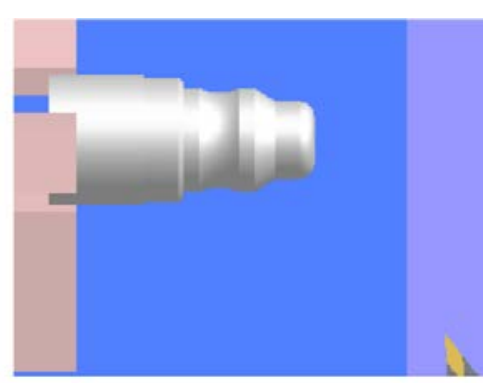

Figure 2 Machining trajectory of simulation parts

\section{The Application of VERICUT in Tool Setting}

Tool setting is the basic operation that must be done before the NC machining. The purpose of the tool setting is to determine the location of the origin of the programming in the machine coordinate system, the point of the cutter point can coincide with the origin of the programming and can also be in anywhere as long as it is in convenient with the tool setting., but the cutter point and the origin of the programming must have a definite coordinate relationship. ${ }^{[5]}$ If we use traditional way of teaching, only explain it in theory, most students will feel difficult to understand. If we use simulation software to demonstrate the movements of lathe tool and workpiece while teaching, students will understand the theory very easily.

For example, the tool setting reference points are located at the center of the right end of the workpiece then the simulation function of NC machining simulation software is demonstrated as follows: 


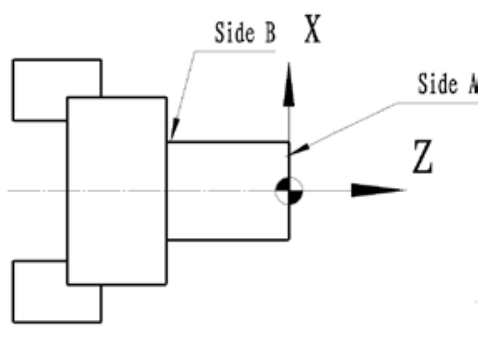

Figure 4 tool setting

(1) Use lathe tool try to cut surface B, after Measure the diameter of the excircle, press OFSETSET $\rightarrow$ [correct] $\rightarrow$ [shape], enter diameter of the excircle”, press [measure] button, then the compensation value of tool $\mathrm{X}$ is automatically entered into the geometry. As shown in Figure 5 and Figure 6.

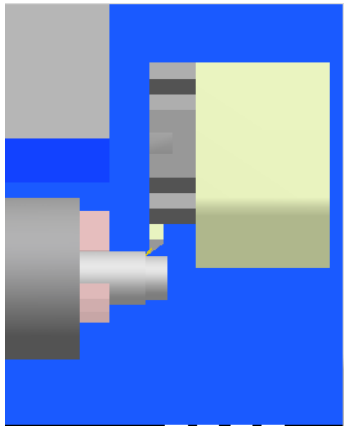

Figure $5 \mathrm{X}$ directed tool setting

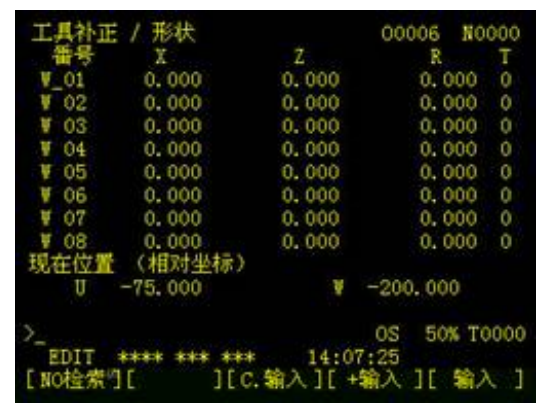

Figure $6 \mathrm{X}$ directed Parameter setting diagram

(2) Use lathe tool try to cut the end of excirle A, press OFSETSET $\rightarrow$ [correct] $\rightarrow$ [shape], enter “Z0", press [measure] button, then the compensation value of tool $\mathrm{Z}$ is automatically entered into the geometry. As shown in Figure 7 and Figure 8.

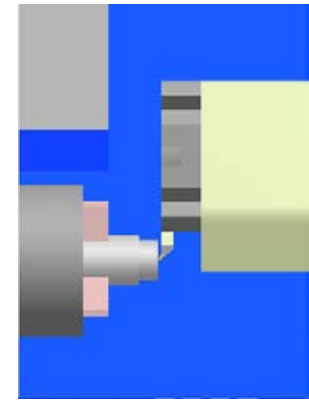

Figure $7 \mathrm{Z}$ directed tool setting

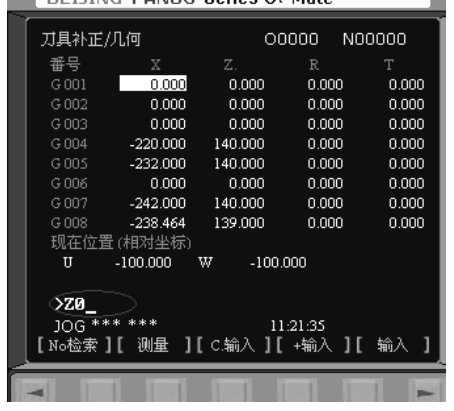

Figure 8 Z directed Parameter setting

\section{The Attention Should Be Paid in Application of VERICUT Software}

Using VERICUT software reasonably and rationally can improve the effect of numerical control teaching. Teachers should pay attention to its application in teaching, however, VERICUT software should also be in an appropriate place in teaching. We should neither rely on it completely and give up the guidance place of the teacher, nor only use chalk-blackboard teaching mode and ignore the application of simulation software. Simulation software should be scientifically and fully play its role in teaching. ${ }^{[4]}$ As a simulation processing software, it can only simulate the processing process rather than the real processing so it can not replace students' real feeling in the real cutting experience and it can not really replace the real machine. As for VERICUT simulation software, although its operating panel is the same as the actual machine tools, it is steel different from the real processing, such as the cutting depth cutting, the tool feed speed selection and the operating procedures are different from the actual processing. It also can not test the processing quality of parts. It is easy for students to neglect the choice of cutting dosage, the selection of NC tools, the clamping method of parts and the control of processing quality. Once the students have done the actual processing, problems may appear such as punching, affecting the actual quality of the 
processing parts and reduce production efficiency and so on. Therefore, the VERICUT software can only be used as an auxiliary tools for students to practice mastering various instructions and operations. Students also need to be arranged for the corresponding hours of CNC machine tool practice and through practical operation of real equipment to make up for the above deficiencies.

\section{Conclusion}

All in all, the teaching quality can be improved significantly by applying VERICUT to the teaching of "numerical control technology" and making full use of its advantages. However, there is a certain gap between VERICUT and actual processing and it can not completely replace the real practical training. The simulation software can serve the teaching and promote the teaching quality as long as it is used scientifically, rationally and effectively in the teaching process. In the course of software teaching, teachers should think positively about the problems that arise in the application, take the measures in time, perfect the teaching methods, and combine the software teaching with the theory teaching closely, so as to exert the best effect of the teaching of NC technology.

\section{References}

[1] Hua Lijuan, Zeng Jianwen. On teaching reform of NC machining technology [J]. Journal of Shanghai Institute of Electrical Technology, 2012.

[2] VERICUT Software Engineering Co., Ltd. VERICUT use manual, 2014.

[3] Sun Jiandong, Shong. NC machine Tool processing technology [M]. Higher education Press, 2012.

[4] Wang Dan, Chen Cunban. Application of Numerical control simulation software in the teaching of NC programming and Machining project [J]. Mechanical engineer, 2014.

[5] Zhou Yue, Ding Xufeng. Practice and exploration on the project teaching of NC machining technology in higher vocational education [J]. Career space, 201102. 